
\title{
ZS Research Suare \\ Antibacterial Activities of Essential Oil and Fractions of Ethanolic extract of Echinops kebericho Tuber
}

\section{Serawit Deyno ( $\nabla$ dserawit@gmail.com )}

Hawassa University https://orcid.org/0000-0001-7126-2815

\section{Derick Hope}

Mbarara University of Science and Technology

Joel PhD Bazira

Mbarara University of Science and Technology

Eyasu Makonnen

Addis Ababa University

\section{Paul E. Alele}

Mbarara University of Science and Technology

\section{Research article}

Keywords: Antimicrobial resistance, Echinops kebericho, fractions, optical density, resazurin assay, minimum inhibitory concentration

Posted Date: February 11th, 2020

DOI: https://doi.org/10.21203/rs.2.23243/v1

License: @ (i) This work is licensed under a Creative Commons Attribution 4.0 International License. Read Full License 


\section{Abstract}

Background: Echinops kebericho is an endemic medicinal plant in Ethiopia traditionally used for treatment of various infectious diseases through different routes of administration such as inhalation, orally chewed, and topically sprayed to affected area. This study investigated antibacterial activity of the essential oil (EO) and the different fractions of ethanolic extract of Echinops kebericho tuber.

Results: MIC of EO ranged from $78.125 \mu \mathrm{g} / \mathrm{ml}-625 \mu \mathrm{g} / \mathrm{ml}$ and it was most active against methicillin resistant $S$. aureus (MRSA, NCTC 12493). Ethyl acetate fraction showed better activity against MRSA (NCTC 12493), MIC = $39.075 \mu \mathrm{g} / \mathrm{ml}$ followed by $E$. faecalis (ATCC 49532), MIC $=78.125 \mu \mathrm{g} / \mathrm{ml}$ and was least active against $K$. pneumonia (ATCC 700603), MIC $=1250 \mu \mathrm{g} / \mathrm{ml}$. MIC of hexane fraction ranged from $156.2-\mu \mathrm{g} / \mathrm{ml}$ to $E$. faecalis (ATCC 49532) to $1250 \mu \mathrm{g} / \mathrm{ml}$ to E. coli (NCTC 11954). Chloroform fraction MIC ranged from $312.5-2500 \mu \mathrm{g} / \mathrm{ml}$; while butanol fraction could be considered pharmacologically inactive as its MIC value is $2500 \mu \mathrm{g} / \mathrm{ml}$ for all and no activity shown for E. coli (NCTC 11954). The MIC of DMSO against all strains ranged 12.5- $25 \% \mathrm{w} / \mathrm{v}$. The MIC estimated by OD measurement correlated well with that of resazurin assay method.

Conclusion: Essential oil and ethyl acetate fraction showed noteworthy antibacterial activity, and MRSA was the most susceptible strain. Further study, however, should be done to investigate the effect on the isolated active component(s).

\section{Background}

Infectious diseases became a re-emerging contemporary global threat to human health with millions of infections and thousands of annual deaths due to antimicrobial resistance (AMR)[1]. AMR is growing at a faster pace than either discovery of new drugs or alternative approaches to tackle it, leaving common infections untreatable [2]. With this resurgence worldwide, the search for novel antimicrobials and alternative approaches to tackle the problem is urgently needed. Modification of existing antibiotics, rediscovering antimicrobials, repurposing antimicrobials, combination treatment, looking for untested sources of antibiotics, and searching for compounds found from chemists around the world are the possible sources of novel antibiotic discovery [3]. Plant based molecules have promising potential for the discovery of novel antimicrobials or as adjuvants in modifying existing antimicrobials $[4,5]$.

Among the many secondary plant metabolites, essential oils of different plant sources showed noteworthy antibacterial activity $[6,7]$ and resistance modulatory effect [8]. The antibacterial activities of EO are mainly attributed to the disruption of membrane enhancing the antibacterial activity of combined antibiotics by increasing their influx [9]. This could contribute significant potential in battling AMR as one of the main contributing factors to the increased resistance in bacteria is the permeability barrier caused by their additional outer membrane [3]. The EOs will infringe the outer membrane barrier restoring the activity of antibiotics. This has led to the exploration of antibiotics-EO combinations in battling the antimicrobial resistance. Studies on antibiotics-EOs combinations from various plant sources have shown synergistic activities [9]. Recently, there is renewed research focused in discovering potential novel antibacterial agents and/adjuvants from plant Eos [5].

Echinops kebericho (Asteraceae) is an endemic medicinal plant which is used for the treatment of various diseases [10]. Ethnomedicinal uses of E. kebericho have been recorded for human and livestock ailments. Reported ailments treated by E. kebericho include wound infections, toothache tonsillitis, stomachache, gonorrhea, 
respiratory manifestations, febrile illness, lung tuberculosis, trypanosmiasis, typhoid, tonsilitis, tooth ache, typhus, common cold, cancer, hypertension, colic, cough, and malaria [11-17]. It is also used to treat scabies, headache, cough, fumigation during childbirth, and mosquito repellent [12]. It is formulated as a water decoction, infusion, smoke inhaled, orally chewed, and topical sprayed to affected area [13, 15-17]. Echinops kebericho was also reported to be used in veterinary practice where root tubers are powdered and mixed with water and given for black leg disease, respiratory manifestations, liver disease, and skin infections [18]. Previous studies revealed flavonoids, alkaloids, triterpenoids, resines, saponins and steroids $[19,20]$ as components and dehydrocostuslactone is also identified [20-23].

The extracts of E. kebericho exhibited a wide range of pharmacological effects including anti-helminthic, antibacterial, antifungal, antidiarrheal, anti-spasmolytic and antimalarial activities. The methanolic root extract and EO showed relatively strong effect $[24,25]$ which established a scientific basis for therapeutic uses of E. kebericho. In vitro and in vivo studies have confirmed the ethnomedicinal use [19, 26-28]. Antibacterial activities from crude extracts $[24,29,30]$ and EOs [25] were reported. Ivan reported anti-mycobacterium activity against Mycobacterium smegmatis and significant antimicrobial resistance modulatory effects [22]. Significant activities were reported against fungi (Aspergillus flavus and Candida albicans) [24], malaria parasite (Plasmodium berghei) [19], Leishmania [26], earthworm [31], and Trypanosoma [32]. Echinops kebericho extract produced a dose dependent reduction in intestinal propulsion and mean defecation comparable to loperamide [27] and EO produced dose-dependent mosquito repellent activity [33] and moderate larvicidal activity [34].

However, the antibacterial activity to different multi-drug-resistant strains and various solvent fractions have not yet been studied. The spectrum of activity and most active component of the extract were not elucidated. Herein, we have determined the antibacterial activity of essential oils and fractions of crude extract to eight strains belonging to five species of bacteria aimed at determining the spectrum of activity and identifying most susceptible strains and paving a way for isolation of most active components against most susceptible strains.

\section{Methods And Materials}

\section{Extraction of the plant material}

Fresh plant tuber was collected from Andracha woreda, Sheka zone, Southwest Ethiopia. The tuber was collected after flowering time in November in the morning as this season was commonly harvesting time. The plant specimen was identified by a taxonomist from Addis Ababa University and voucher specimen (voucher number SD-001/2018) was deposited at the National Herbarium, Department of Biology, and Addis Ababa University. The tuber was rinsed with running water to remove dirt materials. It was then air-dried in shade place away from sun light. In four cycles, five hundred gram of the plant material was soaked with 2 liters of ethanol for 48 hour under agitation. Pounded plant material was dissolved in water in $1 / 5(\mathrm{w} / \mathrm{v})$ ratio in a round bottom glass flask and subjected to hydro-distillation for 3 hours using Clevenger type apparatus. The EO was collected, and the volume and weight were measured.

The ethanolic extract was evaporated on rotary evaporator. Then, dried extract was soaked in distilled water in a separatory funnel. An equal volume of hexane was added, shaken carefully, and allowed to stand until two layers were formed. The hexane layer was separated and the process was repeated three times. Chloroform and nbutanol fractions were prepared following same procedure. The residue of ethanolic extract was soaked in ethyl actate and re-extracted. 
Microorganisms

The bacteria strains used were Staphylococcus aureus (ATCC 29213), S. aureus (MRSA) (NCTC 12493), Enterococcus faecalis (ATCC 29212), Enterococcus faecalis (ATCC 49532), Pseudomonas aeruginosa (ATCC 27853), Escherichia coli (ATCC 25922), E. coli (NCTC 11954), and Klebsiella pneumoniae (ATCC700603).

\section{Preparation, Storage And Testing Reagents}

Resazurin was prepared at $0.015 \%$ by dissolving $0.015 \mathrm{~g}$ in $100 \mathrm{ml}$ of PBS, vortexed, sterilized by microfiltration and stored at $4^{0} \mathrm{c}[35]$.

Preparation And Serial Dilution Of The Extract Solution

Essential oils and fractions/extracts were dissolved in dimethyl sulfoxide (DMSO) for antibacterial activity assay. The final concentration of DMSO was less than or equal to $2 \%$. The stock solution of the extract prepared was $5 \mathrm{mg} / \mathrm{ml}$. This solution was serially diluted with broth forming testing solution ranging from 2.5 to $0.004883 \mathrm{mg} / \mathrm{ml}$. A stock concentration of $128 \mu \mathrm{g} / \mathrm{ml}$ of ciprofloxacillin was prepared serially diluted with the broth forming testing solution ranging from 0.0625 to $64 \mu \mathrm{g} / \mathrm{ml}$. DMSO was also serially diluted with broth.

Preparation And Standardization Of Inoculum

The inocula were prepared in accordance with the Clinical and Laboratory Standards Institute (CLSI) recommendation and standardized to $0.5 \mathrm{McF}$ arland turbidity standards equivalent to $1 \times 10^{8} \mathrm{CFU} / \mathrm{ml}$ using inoculum densitometers. Then it was further diluted to obtain the desired cell density of $5 \times 10^{5} \mathrm{CFU} / \mathrm{ml}[36]$. Briefly, an equivalent of $0.5 \mathrm{McF}$ arland suspensions $\left(1 \times 10^{8} \mathrm{CFU} / \mathrm{ml}\right)$ inoculum was prepared and then diluted 1:20 to yield $5 \times 10^{6} \mathrm{CFU} / \mathrm{ml}$ using saline media. Then, $0.02 \mathrm{ml}$ of this suspension is inoculated into $0.18 \mathrm{ml}$ of broth yielding final concentration of bacteria approximately equal to $5 \times 10^{5} \mathrm{CFU} / \mathrm{ml}$.

\section{Minimum Inhibitory Concentration Determination}

Minimum inhibitory concentration of the EO was determined using broth micro-dilution method [37] and CLSI guideline procedures and safety precautions were strictly followed [38]. Stock solution of EOs in $2 \%$ dimethyl sulfoxide (DMSO) was prepared and then serially diluted in ten two-fold. The 96-well plates were prepared by dispensing into each well first with $100 \mu \mathrm{MHB}$. The EO and the fractions of $100 \mu \mathrm{l}$ were added in the first well and then serially diluted up to the tenth well and the excess $100 \mu \mathrm{l}$ removed from the tenth well. Finally $100 \mu \mathrm{l}$ ofMHB mixed with inoculum was added from the first to eleventh well. The 11th well contains the broth without the intervention while the 12th contains broth without inoculum and intervention. The final volume in each well was $200 \mu \mathrm{L}$. The bacteria were incubated for $24 \mathrm{~h}$ at $36-37^{\circ} \mathrm{C}$. The MIC of DMSO was also evaluated as negative control while ciprofloxacin as positive control. Prior to use, the broth was checked for sterility and fertility. Microbial growth was indicated by an irreversible change in color from the blue of resazurin to pink resofurin after 20 hours of incubation. Minimum bactericidal concentration (MBC) was determined by re-culturing from four well plates which have concentration equal to or greater than the MIC. The plates on which bacterial grow starts to be seen was considered MBC. Measurement of optical density (OD) at $620 \mathrm{~nm}$ were taken at 0,2 418 and 24 hours. Graph of time versus absorbance (OD) versus concentration was plotted at time 0 h, 2 h, 4 h, 18 h, and 20 h. The plot at $18 \mathrm{~h}$ and $20 \mathrm{~h}$ were compared with resazurin assay value for MIC. 


\section{Results}

Essential oil components and fractions of ethanolic extrat of E. kebericho tuber yield

The yield of the EO was $0.18 \% \mathrm{w} / \mathrm{v}$ of dried weight. The fractionation of $96.7 \mathrm{~g}$ of ethanolic extract yielded $34.5 \mathrm{~g}$ hexane, $34.6 \mathrm{~g}$ ethyl acetate, $14.5 \mathrm{~g}$ chloroform, and $13.1 \mathrm{~g}$ butanol fractions. The yield of ethanolic extract was $6.04 \%$, while that of ethyl acetate residual extract was $2.16 \%$ (Fig. 1).

Effect of essential oil of E. kebericho tuber on the bacterial strains

Moderate antibacterial activity of the EO was observed against the tested strains. The activity against methicillin resistant S. aureus was the highest; while least antibacterial activity was observed against S. aureus (ATCC 29213), E. fecalis (ATCC 49532), K. pneumonia (ATCC 700603), P. aeuroginosa, ATCC 27853, and E. coli (ATCC 25922). The MIC value of the EO ranged from $78.125-625 \mu \mathrm{g} / \mathrm{ml}$. The MBC value ranged from 0.1562 to $2.5 \mathrm{mg} / \mathrm{ml}$. Sensitivity to EO varied even among strains of the same species. DMSO did not show inhibition at concentration used for dissolving (2\%) and its MIC value ranged $12.5-25 \% \mathrm{w} / \mathrm{v}$ (Table 1 ).

Table 1

Mean Inhibitory and bactericidal concentration of Echinops kebericho EO against bacterial species

\begin{tabular}{|llllll|}
\hline \multicolumn{2}{|c}{ Microorganisms } & \multicolumn{2}{c}{ Essential oil } & \multicolumn{1}{c|}{ Ciprofloxacillin } & Dimethyl sulfoxide \\
\cline { 3 - 6 } & & MIC $(\mu \mathrm{g} / \mathrm{ml})$ & $\begin{array}{l}\text { MBC } \\
(\mu \mathrm{g} / \mathrm{ml})\end{array}$ & MIC $(\mu \mathrm{g} / \mathrm{ml})$ & MIC $(\%$ W/V) \\
\hline 1. & S. aureus, ATCC 29213 & 625 & 1250 & 0.5 & 12.5 \\
\hline 2. & S. aureus (MRSA), NCTC 12493 & 78.125 & 156.2 & 4 & 12.5 \\
\hline 3. & E. fecalis, ATCC 29212 & 156.2 & 156.2 & 2 & 12.5 \\
\hline 4. & E. fecalis, ATCC 49532 & 625 & 1250 & 4 & 12.5 \\
\hline 5. & K. pneumonia, ATCC 700603 & 625 & 2500 & 8 & 25 \\
\hline 6. & E. coli, ATCC 25922 & 625 & 1250 & 4 & 25 \\
\hline 7. & E. coli, NCTC 11954 & 312.5 & 625 & 8 & 25 \\
\hline 8. & P. aeuroginosa, ATCC 27853 & 625 & 1250 & 1 & 12.5 \\
\hline
\end{tabular}

Graph of OD versus concentration plotted at $18 \mathrm{~h}$ and $20 \mathrm{~h}$ showed MIC and dose dependent effect. The OD of EO treated group is rapidly falling possibly due to bactericidal reducing the viability and the loss of EO through evaporation. The OD measurements at $18 \mathrm{~h}$ and $20 \mathrm{~h}$ indicated the MIC values and the concentration dependent effect of the EO on bacterial cells and well correlated with the value determined using resazurin assay (Fig. 2).

Effect of fractions of ethanolic extract of E. kebericho tuber on the bacterial strains

Of all fractions tested, ethyl acetate fraction showed highest activity followed by hexane fraction, and the butanol fraction showed the least activity of all. MRSA was the most susceptible followed by E. fecalis (ATCC 49532); 
while E. coli (NCTC 11954) was the most resistant strains among the tested strains. No bactericidal activity was observed against E. coli (NCTC 11954) in the tested concentration range (Table 2).

Table 2

Mean Inhibitory and bactericidal concentrations of Echinops kebericho fractions against bacterial species

\begin{tabular}{|c|c|c|c|c|c|c|c|c|c|}
\hline & \multirow[t]{2}{*}{ Microorganisms } & \multicolumn{2}{|c|}{ Hexane fraction } & \multicolumn{2}{|c|}{$\begin{array}{l}\text { Ethyl acetate } \\
\text { fraction }\end{array}$} & \multicolumn{2}{|c|}{$\begin{array}{l}\text { Chloroform } \\
\text { fraction }\end{array}$} & \multicolumn{2}{|c|}{ Butanol fraction } \\
\hline & & $\begin{array}{l}\text { MIC } \\
(\mu \mathrm{g} / \mathrm{ml})\end{array}$ & $\begin{array}{l}\mathrm{MBC} \\
(\mu \mathrm{g} / \mathrm{ml})\end{array}$ & $\begin{array}{l}\text { MIC } \\
(\mu \mathrm{g} / \mathrm{ml})\end{array}$ & $\begin{array}{l}\mathrm{MBC} \\
(\mu \mathrm{g} / \mathrm{ml})\end{array}$ & $\begin{array}{l}\text { MIC } \\
(\mu \mathrm{g} / \mathrm{ml})\end{array}$ & $\begin{array}{l}\text { MBC } \\
(\mu \mathrm{g} / \mathrm{ml})\end{array}$ & $\begin{array}{l}\text { MIC } \\
(\mu \mathrm{g} / \mathrm{ml})\end{array}$ & $\begin{array}{l}\text { MBC } \\
(\mu \mathrm{g} / \mathrm{ml})\end{array}$ \\
\hline 2. & $\begin{array}{l}\text { S. aureus, ATCC } \\
29213\end{array}$ & 625 & 1250 & 312.5 & - & 2500 & - & 2500 & - \\
\hline 3. & $\begin{array}{l}\text { S. aureus, NCTC } \\
12493\end{array}$ & 625 & 625 & 039.075 & 78.125 & 312.5 & 625 & 2500 & - \\
\hline 4. & $\begin{array}{l}\text { E. fecalis, ATCC } \\
29212\end{array}$ & 625 & 1250 & 156.2 & 312.5 & 2500 & - & 2500 & - \\
\hline 5. & $\begin{array}{l}\text { E. fecalis, ATCC } \\
49532\end{array}$ & 156.2 & 625 & 78.125 & 156.2 & 1250 & - & 2500 & - \\
\hline 6. & $\begin{array}{l}\text { K. pneumonia, } \\
\text { ATCC } 700603\end{array}$ & 625 & 1250 & 1250 & - & 2500 & - & 2500 & - \\
\hline 7. & $\begin{array}{l}\text { E. coli, ATCC } \\
25922\end{array}$ & 312.5 & 625 & 312.5 & 625 & 1250 & - & 2500 & - \\
\hline 8. & $\begin{array}{l}\text { E. coli, NCTC } \\
11954\end{array}$ & 1250 & - & 625 & - & 2500 & - & - & - \\
\hline 9. & $\begin{array}{l}\text { P. aeuroginosa, } \\
\text { ATCC } 27853\end{array}$ & 312.5 & 1250 & 312.5 & 625 & 2500 & - & 2500 & - \\
\hline
\end{tabular}

Effect of fractions of ethanolic extract of E. kebericho tuber on S. aureus strains

The methicillin resistant strain (NCTC 12493) was more susceptible compared to the wild type (ATCC 29213) to all E. kebericho fractions. Butanol fraction showed equal effect on both $\mathrm{S}$. aureus strains, and it was the least effective fraction against both strains. The ethyl acetate fraction was the most active fraction against MRSA, while hexane fraction had better activity against wild type (Fig. 3).

Effect of the fractions of ethanolic extract of E. kebericho tuber on E. fecalis strains

Ethyl acetate fraction showed the highest activity followed by hexane fractions among all fractions. The butanol fraction was the least active fraction. Ethyl acetate and hexane fractions showed higher activity against resistant strains (ATCC 49532) compared to wild types (ATCC 29212) (Fig. 4).

Effect of the fractions of ethanolic extract of E. kebericho tuber on E. coli strains 
E. coli strains were the most resistant strains to E. kebericho fractions among all tested strains. Wild types were more susceptible compared to mutant resistant strains. Butanol fractions had the least activity followed by chloroform fraction (Fig. 5).

Effect of the fractions of ethanolic extract of E. kebericho tuber on K. pneumonia (ATCC 700603) and P. aeuroginosa (ATCC 27853)

Similar to other species, ethyl acetate fraction showed the highest activity among all fractions, and the butanol fraction was the least active fraction. P. aeuroginosa appeared to be more susceptible compared to K. pneumonia (Fig. 6).

\section{Discussion}

Eight strains of bacteria belonging to five species investigated for antimicrobial susceptibility to EO and fractions/extract of E. kebericho demonstrated a range of susceptibilities. Essential oil and ethyl acetate fraction exhibited higher activity against most bacteria tested compared to the fractions perhaps due to the presence of the most active component(s) in the EO. Resazurine assay method worked and matched well with OD measurement. However, the OD measurement value for EO was dropping with time due to evaporation. The reduction of OD measurement decreased the concentration of EO and consequently its activity. The orders of activity of the fractions were ethyl acetate followed by hexane fraction and then chloroform and finally butanol fraction was the least active. The highest antibacterial effect of ethyl acetate fraction could be attributed to the type of chemical compound present in the fraction indicating the component(s) is/are most active. N-hexane removes all non-polar compounds, chloroforms all pigments (such as chlorophyll), and while ethyl acetate takes all biological active compounds and n-butanol extracts all other hydrocarbons. The results of previous studies [39] were in agreement to those of the present study where extraction by different solvents showed different activities. The highest antibacterial activity of ethyl acetate fraction compared to crude extract and/or fractions were also reported in previous studies $[40,41]$.

Gram-positive species were more susceptible to both the EO and fractions compared to gram-negative species. Significant variation in the activity of the same fraction towards strains of the same species was observed in the case of S. aureus and E. feacalis. In both cases, resistant strains were more susceptible compared to wild type. Methicillin resistant S. aureus (MRSA), mecA positive was more susceptible to EO and ethyl acetate fraction compared to a wild type strain ATCC 29213. Similar finding was also recorded with epigallocatechin Gallateb (plant extract) where S. aureus ATCC 29213 was less susceptible compared to MRSA strains, possibly due to an increasing affinity of the extract to mutated proteins of MRSA [42]. Mutation is an energy demanding process, and it results in increased susceptibility to a naive stress compared to wild type. Previous studies had outlined increased overall antibiotic susceptibility to new antimicrobial agents in S. aureus mutants [43]. The increased susceptibility of mutant strains of S. aureus and E. feacalis in the current study could indicate that mutation favors susceptibility.

Greater susceptibility of gram-positive species compared to gram-negative was ascribed to differences in their cell wall structures. The gram-negative outer membranes are diffusional barriers making bacteria less susceptible to many antimicrobial agents [44]. Gram-positive mutant strains were susceptible compared to wild type but more resistance was observed in gram-negative mutant strains. This could be due to membrane alteration in gramnegatives favoring more resistance which was also shown in previous study where reduced outer membrane 
permeability contributed to enhanced resistance of E. coli 0157:H7 to antimicrobial agents [45]. Gram-positive bacteria are known to be more susceptible to EO than gram-negative bacteria. E. coli was least susceptibile to EO in the present study which was in agreement with the previous finding [46]. Resistance of gram-negative bacteria was in most cases ascribed to the presence of complex resistant outer membrane $[47,48]$.

The antibacterial activity of the EO could be attributed to their membrane disruptive property [49]. Cinnamon EO, for example, have been reported to damage cell membrane; alter lipid profile; inhibit ATPases, cell division, membrane porins, motility, and biofilm formation; and anti-quorum sensing effects. In general, EOs destabilize the cellular architecture, leading to the breakdown of membrane integrity and increased permeability, which interrupts many cellular activities, including energy production, membrane transport, and other metabolic regulatory functions. Membrane disruption affects various vital cellular processes, nutrient processing, the synthesis of structural macromolecules, and the secretion of growth regulators [50]. The findings of the current study where more non-polar fractions and EO possess higher antibacterial activities could be due to the membrane disruptive potential.

From a clinical perspective, natural products exhibiting antibacterial activities with MIC values over $1 \mathrm{mg} / \mathrm{ml} \mathrm{have}$ little relevance as a number of relatively inert substances may display activity at this and/or above concentration [51]. Butanol fraction could be considered pharmacologically inactive as MIC of all of the strains was greater than or equal to $2.5 \mathrm{mg} / \mathrm{ml}$ indicating the removal of active components by more non-polar solvents. Previous studies on the plant had also indicated better activity of EO and non-polar components [22, 52]. Researchers consider that only plant extracts with MICs lower than $0.1 \mathrm{mg} / \mathrm{ml}$ are interesting in a search for potential new antibiotics [53]. The current study, thus, revealed that the EO and ethyl acetate fraction deserve further research for new potential antibacterial agents.

The OD of EO had decreased from baseline value which could possibly be due to either volatilization of the EO at incubation temperature $\left(36-37^{0} \mathrm{c}\right)$ or increased solubility at increased temperature. If the reduction in OD is due to volatilization, this would have reduced the antibacterial activity. Essential oils therapeutic utilization was highly impaired by their chemical instability including volatilization and auto-oxidation in air. Microencapsulation has been utilized for stabilizing and worked well in the previous study [54]. Their toxicity profile in systemic use has not yet been fully explored though some small studies elucidated their safety. With their limited data on systemic use, they can still continue to be used for topical purposes. Our recent reviews established EO as viable topical antiinfective agents [55].

In conclusion, this study revealed noteworthy antibacterial activities of EO and ethyl acetate fraction of ethanolic extract of E. kebericho tuber. MRSA was the most susceptible strain and resistant gram-positive strains were more susceptible compared to wild type. Further study, however, should be done to investigate the antibacterial effect of the isolated active component(s).

\section{Acronyms}

ATCC: American Type Culture Collection

CLSI: Clinical and Laboratory Standards Institute

DMSO: Dimethyl sulfoxide, 
EO: Essential oil

MBC: Minimum bactericidal concentration

MHB: Muller-Hinton broth

MIC: Minimum inhibitory concentration

MRSA: Methicillin-resistant Staphylococcus aureus

NCTC: National Collection of Type Cultures

OD: Optical density

\section{Declarations}

\section{Ethics Approval and Consent to Participate}

The protocol of this study was reviewed by Faculty Research Committee and approved by the Research Ethics Committee (REC) of Mbarara University of Science and Technology, Uganda. It was also registered with Uganda National Council for Science and Technology (UNCST) with reference number HS398ES.

\section{Competing interests}

The authors declare that they have no competing interests.

\section{Funding}

This study was funded by World Bank through Pharm-Biotechnology and Traditional Medicine Centre (PHARMBIOTRAC), African Center of Excellence II (ACE-II) Project. The funder contributed research money and stipends (SD) but has not involved in planning and implementation of the study.

\section{Authors' Contributions}

SD conceived the research idea. SD and DH conducted the experiment. EM, JB, PEA developed the concept, monitored and mentored the proposal development. SD wrote the draft manuscript. All authors revised, edited and approved the final manuscript.

\section{Consent for publication}

Not applicable

\section{Availability of Data and Materials}

The dataset supporting the conclusions of this article is included within the article.

\section{Acknowledgements}

We would like to thank Pharm-biotechnology and Traditional Medicine Center of Excellence (PHARMBIOTRAC) World Bank African center of excellence II (ACE-II) project for funding the research. We appreciate Dr. Casim Umba 
Tolo and Dr. Patrick Engue Ogwang for facilitating the research fund. We would like to extend our appreciation to Médecins Sans Frontières, Epicentre Uganda for providing facility and microbial strains.

\section{References}

1. Holmstrup P, Klausen B. The growing problem of antimicrobial resistance. Oral Dis. 2018;24:291-5.

2. WHO. World health organization releases global priority list of antibiotic-resistant bacteria to guide research, discovery, and development of new antibiotics. Medknow Publications; 2017.

3. Schneider EK, Reyes-Ortega F, Velkov T, Li J. Antibiotic-non-antibiotic combinations for combating extremely drug-resistant Gram-negative 'superbugs' . 2017; 61. EEssays Biochem. 2017;61:115-25.

4. Yang S-K, Low L-Y, Yap PS-X, Yusoff K, Mai C-W, Lai K-S, et al. Plant-Derived Antimicrobials: Insights into Mitigation of Antimicrobial Resistance. Rec Nat Prod. 2018;12.

5. da Silva LCN, da Silva M V, Correia MT. New Frontiers in the Search of Antimicrobials Agents from Natural Products. Front Microbiol. 2017;8:210.

6. Dorman HJD, Deans SG. Antimicrobial agents from plants: antibacterial activity of plant volatile oils. J Appl Microbiol. 2000;88:308-16.

7. Artini M, Patsilinakos A, Papa R, Božović M, Sabatino M, Garzoli S, et al. Antimicrobial and antibiofilm activity and machine learning classification analysis of essential oils from different mediterranean plants against pseudomonas aeruginosa. Molecules. 2018;23:482.

8. Hammer KA, Carson CF, Riley T V. Effects of Melaleuca alternifolia (tea tree) essential oil and the major monoterpene component terpinen-4-ol on the development of single-and multistep antibiotic resistance and antimicrobial susceptibility. Antimicrob Agents Chemother. 2012;56:909-15.

9. Langeveld WT, Veldhuizen EJA, Burt SA. Synergy between essential oil components and antibiotics: a review. Crit Rev Microbiol. 2014;40:76-94.

10. Alemayehu G. Plant Diversity and Ethnobotany of Medicinal and Wild Edible Plants in Amaro District of Southern Nations, Nationalities and Peoples Region and Gelana District of Oromia Region, Southern Ethiopia. 2017.

11. Megersa M, Jima TT, Goro KK. The Use of Medicinal Plants for the Treatment of Toothache in Ethiopia. Evidence-Based Complement Altern Med. 2019;2019.

12. Bitew H, Hymete A. The Genus Echinops: Phytochemistry and Biological Activities: A Review. Front Pharmacol. 2019;10.

13. Teklehaymanot T, Giday M, Medhin G, Mekonnen Y. Knowledge and use of medicinal plants by people around Debre Libanos monastery in Ethiopia. J Ethnopharmacol. 2007.

14. Abebe D. Proceedings of the Workshop on Development and Utilization of Herbal Remedies in Ethiopia. Ethiopian Health and Nutrition Research Institute; 1996.

15. Teklehaymanot T, Giday M. Ethnobotanical study of medicinal plants used by people in Zegie Peninsula, Northwestern Ethiopia. J Ethnobiol Ethnomed. 2007;3:12. doi:10.1186/1746-4269-3-12.

16. Abera B. Medicinal plants used in traditional medicine by Oromo people, Ghimbi District, Southwest Ethiopia. J Ethnobiol Ethnomed. 2014;10:40. doi:10.1186/1746-4269-10-40.

17. Kloos H. Preliminary studies of medicinal plants and plant products in markets of central Ethiopia. Arbeitskreis Ethnomedizin; 1977. 
18. Yigezu Y, Haile DB, Ayen WY. Ethnoveterinary medicines in four districts of Jimma zone, Ethiopia: cross sectional survey for plant species and mode of use. BMC Vet Res. 2014;10:76. doi:10.1186/1746-6148-10-76.

19. Toma A, Deyno S, Fikru A, Eyado A, Beale A. In vivo antiplasmodial and toxicological effect of crude ethanol extract of Echinops kebericho traditionally used in treatment of malaria in Ethiopia. Malar J. 2015;14.

20. Abegaz BM, Tadesse IM, Majinda R. Distribution of Sesquiterpene Lactones and Polyacetylenic Thiophenes in Echinops. Biochem Syst Ecol. 1991;19:323-8.

21. Hymete A, Hailu A, Rohloff J. In vitro Evaluation of Antileishmanial Activity and Toxicity of Essential Oils of Artemisia absinthium and Echinops kebericho. Chem Biodivers. 2011;8:614-23.

22. Ivana T. Phytochemische und antimikrobielle Untersuchung an Echinops kebericho Mesfin. MSc Thesis. 2015.

23. Hymete A, Afifi MS. Investigation of the Fixed Oil Isolated from the Roots of Echinops kebericho Mesfin. Mansoura. J Pharmacol Sci. 1997;13:59-69.

24. Ameya G, Gure A, Dessalegn E. Antimicrobial activity of Echinops kebericho against human pathogenic bacteria and fungi. 2016;13:199-203.

25. Belay G, Tariku Y, Kebede T, Hymete A, Mekonnen Y. Ethnopharmacological investigations of essential oils isolated from five Ethiopian medicinal plants against eleven pathogenic bacterial strains. Phytopharmacology. 2011;1:133-43.

26. Tariku Y, Hymete A, Hailu A, Rohloff J. In vitro evaluation of antileishmanial activity and toxicity of essential oils of Artemisia absinthium and Echinops kebericho. Chem Biodivers. 2011;8:614-23.

27. Shiferie F, Shibeshi W. In vivo antidiarrheal and ex-vivo spasmolytic activities of the aqueous extract of the roots of Echinops kebericho Mesfin ( Asteraceae ) in rodents and isolated guinea-pig ileum. Int J Pharm Pharmacol. 2013;2:110-6.

28. Turek I. Phytochemical and anitimicrobial research of Echinops kebericho Mesfin Phytochemische und antimikrobielle Untersuchung an Echinops kebericho Mesfin. 2015; December.

29. Ashebir M, Ashenafi M. Evaluation of the antibacterial activity of crude preparations of Zingiber officinale (zingibl), Echinops spp.(kebericho), Coriandrum sativum (dimbilal) and Cymbopogan citratus (tej sar) on some food-borne pathogens. Ethiop J Health Sci. 1999;9.

30. Desta B. Ethiopian traditional herbal drugs . Part II: Antimicrobial activity of 63 medicinal plants. 1993;39:129-39.

31. Hymete A, Kidane A. Screening for anthelmintic activity in two Echinops spp. Ethiop. Pharm J. 1991;9:67-71.

32. Abdeta D. In vitro and in vivo antitrypanosomal effects of hydromethanolic extract of Solanum anguivi fruits and Echinops kebericho roots. Addis Ababa University (thesis); 2016.

http://etd.aau.edu.et/bitstream/handle/123456789/2564/Debela Abdela.pdf?sequence=1\&isAllowed=y.

33. Jemberie W, Tadie A, Enyew A, Debebe A, Raja N. Repellent activity of plant essential oil extracts against malaria vector Anopheles arabiensis Patton (Diptera: Culicidae). ENTOMON. 2016;41 2 SE-Articles. http://entomon.in/index.php/Entomon/article/view/166.

34. Abebe D, Mudie K, Zeleke G. Screening of some Ethiopian medicinal plants for mosquito larvicidal effects and phytochemical constituents. Pharmacologyonline. 2007;3:231-43.

35. Elshikh M, Ahmed S, Funston S, Dunlop P, McGaw M, Marchant R, et al. Resazurin-based 96-well plate microdilution method for the determination of minimum inhibitory concentration of biosurfactants. Biotechnol Lett. 2016;38:1015-9.

Page $11 / 16$ 
36. Patel BP, Cockerill FR, Bradford PA, Eliopoulos GM, Hindler JA, Jenkins SG. M07-A10 Methods for Dilution Antimicrobial Susceptibility Tests for Bacteria That Grow Aerobically; Approved Standard-. 2015.

37. Eloff JN. A sensitive and quick microplate method to determine the minimal inhibitory concentration of plant extracts for bacteria. Planta Med. 1998;64:711-3.

38. CLSI. Methods for dilution antimicrobial susceptibility tests for bacteria that grow aerobically. National Committee for Clinical Laboratory Standards; 2018.

39. Kotzé M, Eloff JN. Extraction of antibacterial compounds from Combretum microphyllum (Combretaceae). South African J Bot. 2002.

40. Geidam YA, Ambali AG, Onyeyili PA. Phytochemical screening and antibacterial properties of organic solvent fractions of Psidium guajava aqueous leaf extracts. Int J Pharmacol. 2007.

41. Gnan SO, Demello MT. Inhibition of Staphylococcus aureus by aqueous Goiaba extracts. J Ethnopharmacol. 1999.

42. Betts JW, Sharili AS, Phee LM, Wareham DW. In vitro activity of epigallocatechin gallate and quercetin alone and in combination versus clinical isolates of methicillin-resistant Staphylococcus aureus. J Nat Prod. 2015;78:2145-8.

43. Ling B, Berger-Bächi B. Increased Overall Antibiotic Susceptibility inStaphylococcus aureus femAB Null Mutants. Antimicrob Agents Chemother. 1998;42:936-8.

44. Ghai I, Ghai S. Exploring bacterial outer membrane barrier to combat bad bugs. Infect Drug Resist. 2017;10:261.

45. Martinez MB, Flickinger M, Higgins L, Krick T, Nelsestuen GL. Reduced outer membrane permeability of Escherichia coli 0157: H7: suggested role of modified outer membrane porins and theoretical function in resistance to antimicrobial agents. Biochemistry. 2001;40:11965-74.

46. Inouye S, Takizawa T, Yamaguchi H. Antibacterial activity of essential oils and their major constituents against respiratory tract pathogens by gaseous contact. J Antimicrob Chemother. 2001;47:565-73.

47. Mann CM, Cox SD, Markham JL. The outer membrane of Pseudomonas aeruginosa NCTC 6749 contributes to its tolerance to the essential oil of Melaleuca alternifolia (tea tree oil). Lett Appl Microbiol. 2000;30:294-7.

48. Onawunmi GO, Ogunlana EO. Effects of lemon grass oil on the cells and spheroplasts of Escherichia coli NCTC 9001. Microbios Lett. 1985;28:63-8.

49. Vasconcelos NG, Croda J, Simionatto S. Antibacterial mechanisms of cinnamon and its constituents: A review. Microb Pathog. 2018;120:198-203.

50. Zhang Y, Liu X, Wang Y, Jiang P, Quek SY. Antibacterial activity and mechanism of cinnamon essential oil against Escherichia coli and Staphylococcus aureus. Food Control. 2016.

51. Gibbons S. Anti-staphylococcal plant natural products. Nat Prod Rep. 2004;21:263-77.

52. Belay G, Tariku Y, Kebede T, Hymete A, Yalemtsehay M. Antibacterial activity of five oil bearing Ethiopian medicinal plants against eleven pathogenic bacterial strains. 2011; March 2017.

53. Eloff JN. Avoiding pitfalls in determining antimicrobial activity of plant extracts and publishing the results. BMC Complement Altern Med. 2019;19:106. doi:10.1186/s12906-019-2519-3.

54. Guarda A, Rubilar JF, Miltz J, Galotto MJ. The antimicrobial activity of microencapsulated thymol and carvacrol. Int J Food Microbiol. 2011. 


\section{Figures}

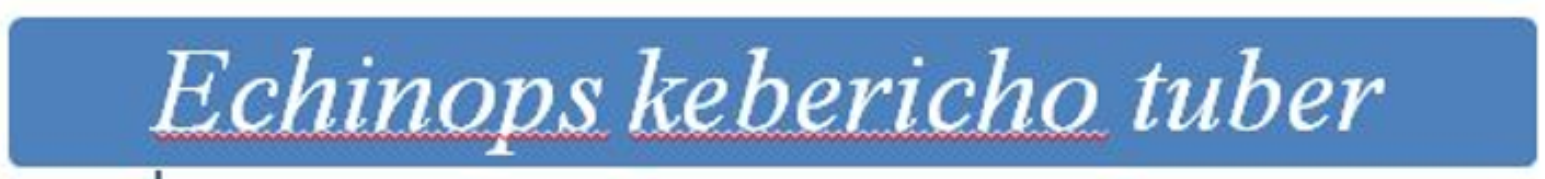

\section{Fresh tuber pounded and hydro- distilled, yield $=0.18 \% \mathrm{w} / \mathrm{v}$}

Dried tuber powdered and extracted with ethanol $(1.6 \mathrm{~kg})$, Yield $=96.7 \mathrm{~g}$

- Fractionated to

- Hexane (yield =34.5 g)

- Chloroform (yield = $14.5 \mathrm{~g}$ )

- Ethyl acetate ( yield = $34.6 \mathrm{~g}$ )

- Butanol (yield = $13.1 \mathrm{~g}$ )

Figure 1

Depicts the extraction procedure and the yield 

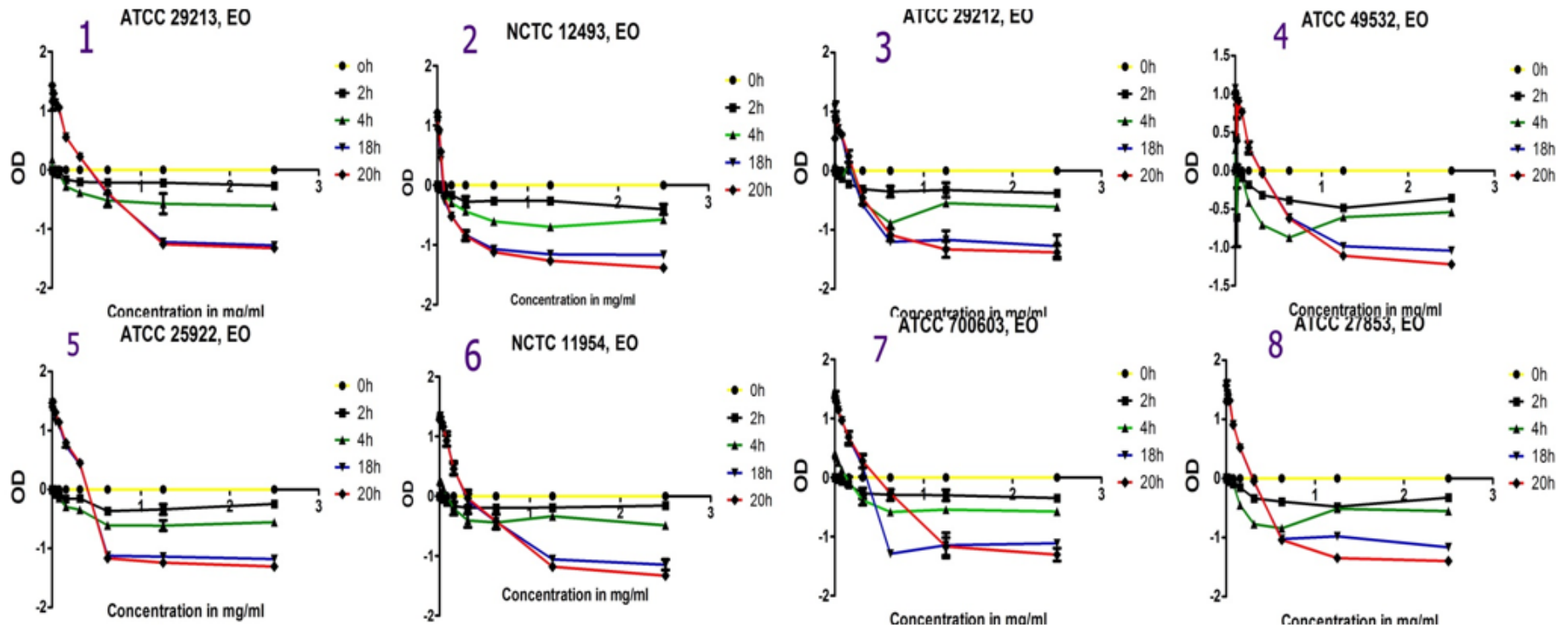

Figure 2

Graph of concentration versus absorbance (optical density) showing growth curve, MIC and dose dependent effect on EO treated bacteria. The MIC can be considered where the graph of the curve for the 18 hour or 20 hour crosses or approximates $x=0$ line. Number 1-8 respectively indicates bacterial strains; ATCC 29213, NCTC 12493, ATCC 29212, ATCC 49532, ATCC 700603, ATCC 25922, NCTC 11954, and ATCC 27853.
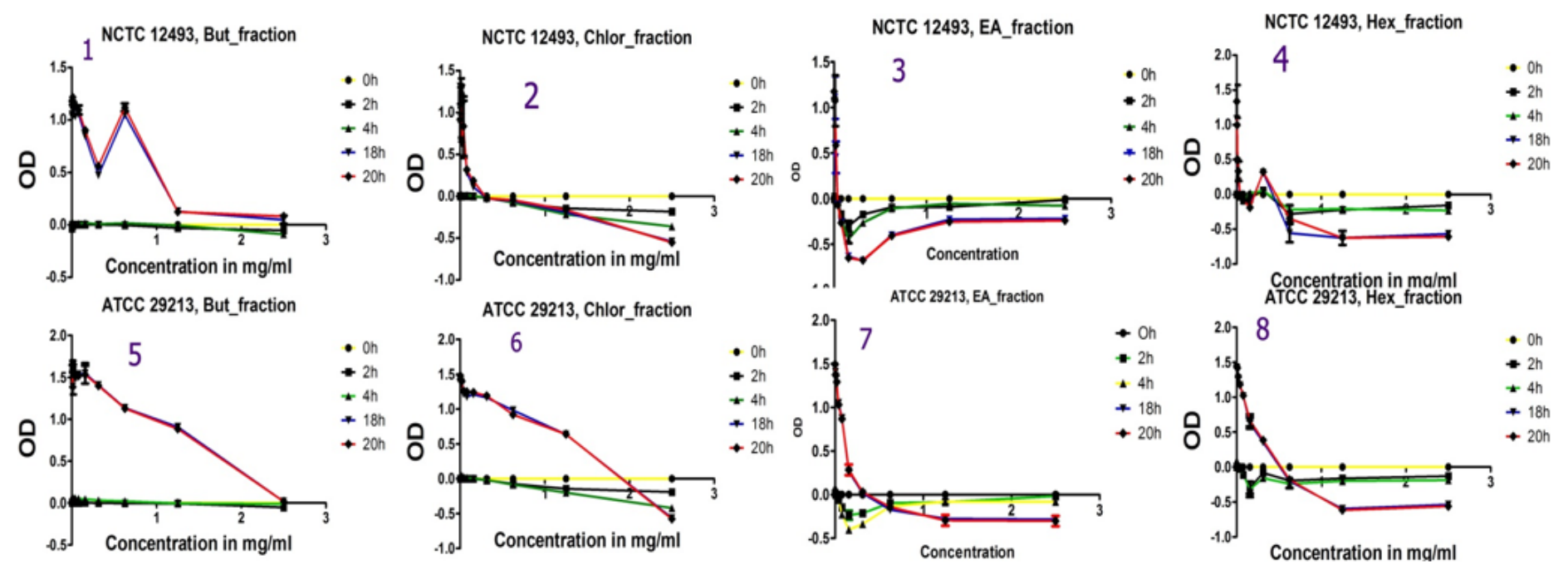

\section{Figure 3}

Graph of OD versus concentration showing growth curve, MIC and dose dependent effect on S. aureus (ATCC 29213 and NCTC 12493). The MIC could be considered where the curve of graph for the 18 hour and /or 20 hour crosses or approximates $x=0$ line. Figures numbered 1-4 indicate MRSA (NCTC 12493) while 5-8 indicate ATCC 29213. Note: But._fraction = butanol fraction, Chlor_fraction $=$ Chloroform fraction, EA_fraction $=$ Ethyl acetate fraction. 


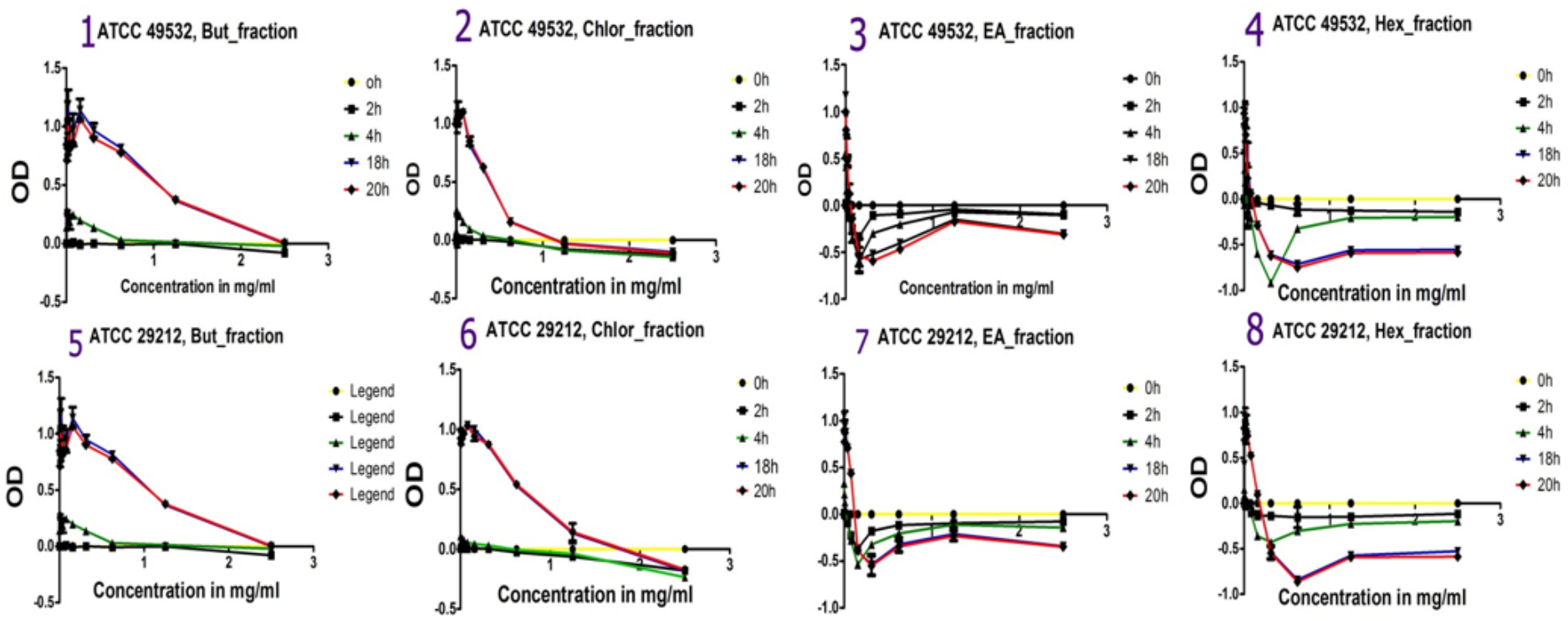

Figure 4

Graph of OD versus concentration showing growth curve, MIC and dose dependent effect on E. fecalis (ATCC 29212, ATCC 49532). The MIC could be considered where the graph of the curve for the 18 hour and /or 20 hour crosses or approximates $x=0$ line. Figures numbered 1-4 indicate resistant strains (ATCC 49532) and 5-8 indicate the wild type (ATCC 29212). Note: But_fraction = butanol fraction, Chlor_fraction = Chloroform fraction, EA_fraction $=$ Ethyl acetate fraction.
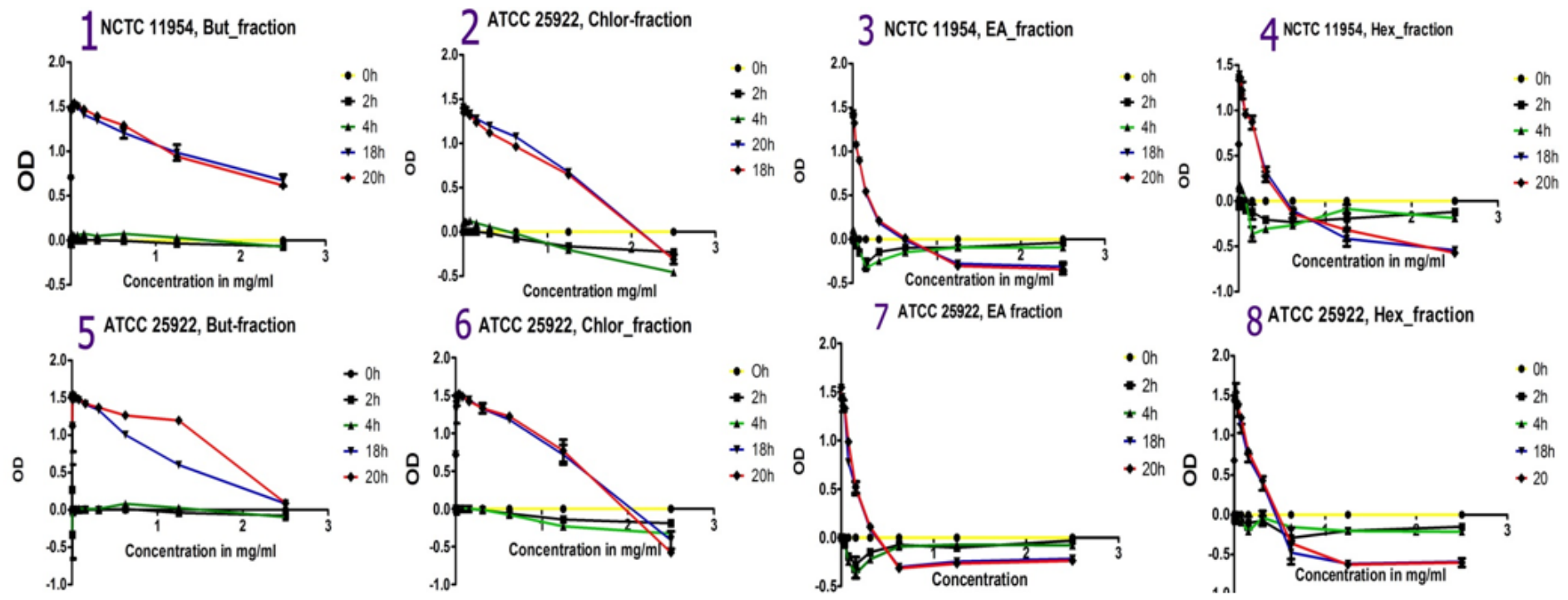

8 ATCC 25922, Hex_fraction

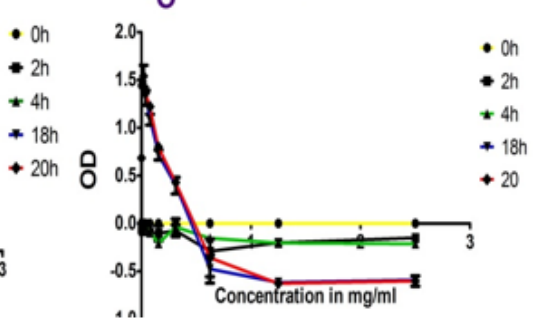

Figure 5

Graph of OD versus concentration showing growth curve, MIC and dose dependent effect on E. coli (ATCC 25922, ATCC 11954). The MIC could be considered where the graph of the curve for the 18 hour and /or 20 hour crosses or approximates $x=0$ line. Figures numbered 1-4 indicate the resistant strains (ATCC 11954) and 5-8 indicated the wild type (ATCC 25922). Note: But_fraction = butanol fraction, Chlor_fraction = Chloroform fraction, EA_fraction = Ethyl acetate fraction. 

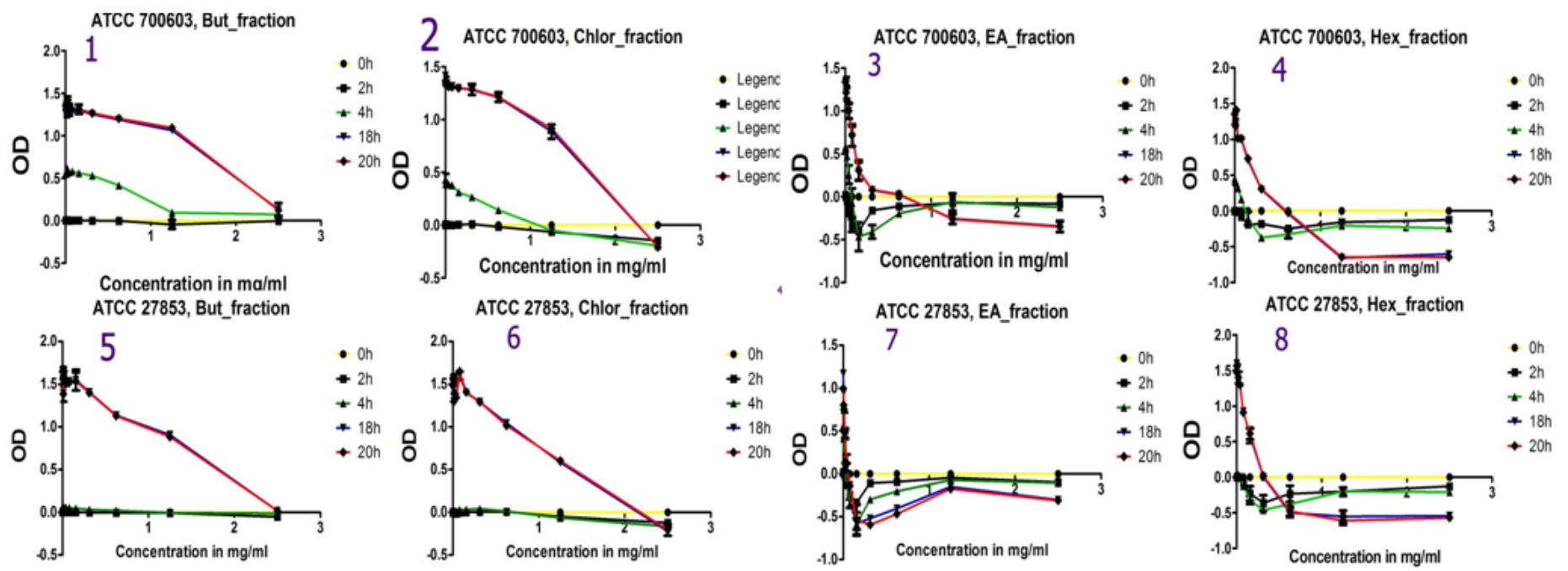

\section{Figure 6}

6: Graph of OD versus concentration showing growth curve, MIC and dose dependent effect on P. aeuroginosa (ATCC 27853) and K. pneumonia (ATCC 700603). The MIC could be considered where the curve of the graph for the 18 hour and /or 20 hour crosses or approximates $x=0$ line. Figures numbered 1-4 indicate K. pneumonia (ATCC 700603) and 5-8 indicate P. aeuroginosa (ATCC 27853). Note: But_fraction = butanol fraction, Chlor_fraction = Chloroform fraction, EA_fraction = Ethyl acetate fraction. 